\title{
ACADEMIC SELF-EFFICACY, GENDER AND ACADEMIC PROCRASTINATION
}

\author{
Ajayi Oluwagbemiga Samson
}

\author{
University of Ilorin
}

\begin{abstract}
Academic procrastination has been described as a behaviour in which academic tasks such as preparing for exams, preparing term papers, managing administrative affairs related to school and fulfilling attendance responsibilities are postponed till another time. Research findings have supported the fact that this habit stems from either failure in self-regulation (passive procrastination) or from utilitarian purposes (active procrastination). This study explores the prevalence of academic procrastination and the prevalent type of procrastinators among undergraduate students. It also examines the difference in academic self-efficacy of passive and active undergraduate procrastinators, as well as gender association between passive and active undergraduate procrastinators. It further determines gender difference in procrastinatory behaviour of university undergraduates. A descriptive survey design was adopted. A total of 200 undergraduate students randomly selected from five faculties from University of Ilorin constitute the sample size for this study. Three research instruments used to collect data for this study are: College Academic Self-Efficacy Scale (CASES), Tuckman Academic Procrastination Scale (TAPS) and Active Procrastination Scale. Results reveal that $29.0 \%$ of undergraduate students are procrastinators and $51.7 \%$ of the procrastinators are the passive type. No significant difference is found in academic self-efficacy of passive and active procrastinators, $t(56)=1.038$, $p>.05$, and gender is not significantly associated with passive and active undergraduate procrastinators, $\chi 2(n=58)=$ $1.752, \mathrm{df}=1, \mathrm{p}=.186$. It has also been found that no significant gender difference exists in procrastinatory behaviour of male and female university undergraduates, $t(56)=.168, p>.05$. This study concludes that most of the university undergraduates that engage in procrastinatory behaviour are passive in nature and neither academic self-efficacy nor gender of the students is a significant factor in their procrastinatory behaviour.
\end{abstract}

Keywords: Academic procrastination, self-efficacy, procrastinatory behaviour. 


\section{Introduction}

Individuals are known to differ in personal traits they possess. These observed differences in personal characteristics tend to influence the behaviour of individuals, including decision making about how and when a particular task has to be done. These individual distinctions, evident in a person's approach to decision making and implementing, also extend their tentacles to the academic life of learners. This may, therefore, culminate into engaging in the act of shifting what has to be done presently till another time, which is generally described as procrastination.

The origin of the term procrastination has been traced to two Latin words: "pro", translating to forward motion, and "crastinus", referring to belonging to tomorrow. Since the term procrastination has attracted the attention of researchers, it has been looked into from different perspectives. For instance, Kachgal, Hansen and Nutter (2001) defined procrastination as a trait or behavioural disposition reflected in the tendency to postpone or delay performing a task or making decisions. Others, such as Freeman, Cox-Fuenzalida and Stoltenberg (2011); Gupta, Hershey and Gaur (2012); and Rozental and Carlbring (2013), described procrastination as an act of purposeful voluntary delay in beginning or finishing a task that should ideally be completed in the present time until the last minute or after the predetermined deadline or indefinitely. Balkis and Duru (2007) operationalized five different dimensions or categories through which procrastinatory behaviours can be exhibited to include life routine, decisional, neurotic, compulsive, and academic procrastination.

According to Balkis and Duru (2007), there seems to be a possibility for individuals exhibiting procrastinatory behaviour in any of the identified dimensions of procrastination to also manifest it in the other aspects of their behaviour. However, educational researchers seem to deem it fit to investigate procrastinatory behaviour in academic settings more than in the other aspects of human routine.

\section{Academic Procrastination}

Academic procrastination refers to a situation in which academic tasks such as preparing for exams, preparing term papers, managing administrative affairs related to school and fulfilling attendance responsibilities are postponed till another time (Özer, Demir, \& Ferrari, 2009). Procrastination behaviour seems to be rampant among undergraduates due to the nature of the activities involved in their learning process. A typical undergraduate at one time or another will have to face a myriad of activities related to meeting either academic, social or emotional needs on campus. Popoola (2005) also observed that lives of university students are characterized by frequent deadlines, usually imposed by their lecturers and administrators, to carry out various responsibilities such as registration for courses, completion of course forms and submission of class assignments or term papers. Experience has shown that these tasks often have to be performed simultaneously.

Interest in the study of academic procrastination among scholars seems to have arisen due to its prevalence and debilitating effects on students' academic success and psychological well-being. Several studies (Beck, Koons, \& Milgrim, 2000; Fritzsche, Young, \& Hickson, 2003; Akinsola, Tella, \& Tella, 2007; Savithri, 2014; Kim \& Seo, 2015) have attributed undergraduates' poor academic performance to academic procrastination. In a similar vein, Aderanti, Williams, Oyinloye and Uwanna (2013) found a significant relationship between academic procrastination of students and instances of academic rebelliousness, such as their involvement in examination malpractices. Academic procrastination has also been linked to many negative outcomes such as low self-esteem and delay in task completion (Ferrari \& Emmons, 1995); low grades (Tice \& Baumeister, 1997); and generally poor academic performance (Wesley, 1994; Tuckman, Abry \& Smith, 2002).

Regarding the prevalence of academic procrastination, studies such as Schubert, Lilly, and Stewart (2000) and Steel and Ferrari (2013) estimate procrastination prevalence rate among college students to be $80 \%$ and this problem is reported as one of the most common among post-secondary students, where the estimate ranges from $10 \%$ to $70 \%$. Onwueglouzie (2004) indicates that approximately $40 \%$ to $60 \%$ of college students always or often procrastinate in such academic tasks as writing papers, preparing for tests, and reading assignments weekly. Balkis and Duru (2007) estimate academic procrastination among American college students to be $95 \%$, with at least $46 \%$ of the students reporting procrastination on academic tasks at least half of the time. According to Abu-Ghazal (2012) not less than $25 \%$ of university students are reported to be procrastinators. 


\section{Active and Passive Procrastinators}

Procrastination has been described as a failure in self-regulation (Steel, 2007). This is because it is believed that counterproductive behaviours, such as avoidance in commencing or completing a task, setting poor goals or making poor decisions, result from ineffective time and behaviour management (Howell \& Watson, 2007; Steel, 2007; Wolters, 2003). While some scholars argue against the inclusion of purposeful delay as a part of procrastination, others admit it as a component. This purposeful or deliberate delay is termed active procrastination.

Active procrastination is defined as deliberate postponement of executing or implementing actions for utilitarian purposes. These purposes, according to Wang, Sperling and Haspel (2015), include aroused incentive to achieve optimum performance, increased challenge for less motivating tasks or enhanced effectiveness through increased task focus. In other words, active procrastination is a less debilitating and more regulatory pattern of behaviour whereas passive procrastination is characterized by irrational and counterproductive delay. Passive procrastinators are known to be deficient in implementing tasks as planned, with weak ability to manage time in an efficient manner (Bembenutty \& Karabenic, 2004).

Active procrastinators have been distinguished from passive ones on three motivational self-regulatory aspects. In terms of behaviour, active procrastinators are capable of turning in the task when due and believe that completing the task ahead of time does not add to its quality. The cognitive aspect is their ability to act on their decision through putting off a task so as to maximize resources to complete it. The feeling of a little discomfort but high motivation resulting from working under pressure explains the affective aspect of procrastination (Chu \& Choi, 2005; Choi \& Moran, 2009).

\section{Academic Procrastination and Academic Self-efficacy}

One of the factors contributing to timely academic tasks, decision making and implementation is an individual learners' academic self-efficacy belief. According to Bandura, self-efficacy affects an individual's choice of activities, efforts expended, and persistence. Self-efficacy refers to an individual's judgment of his/her capabilities to successfully perform given tasks (Schunk, 1991). Zimmerman
(2000) refers to self-efficacy as a multidimensional construct which varies according to the domain of demands while Pajares (1996) opines that its evaluation has to be at a level specific to the outcome domain. Abd-Elmotaleb and Saha (2013), however, caution that what should be measured in academic setting is academic self-efficacy rather than generalized self-efficacy. These authors define academic self-efficacy as an individual learner's personal judgment of his/her capabilities to organize and execute courses of actions in order to attain designated types of educational performances. Learner's self-efficacy belief may serve as a motivating force propelling learners in carrying out academic tasks at any given time.

According to Bandura (1993) people's beliefs in their capabilities to undertake a particular task influence the type of anticipatory scenarios they construct and rehearse. There is a tendency for learners with a high sense of efficacy to visualize success scenarios that provide positive guides and supports for performance, whereas learners who doubt their efficacy in carrying out a particular academic task usually visualize failure scenarios and preoccupy themselves with self-defeating thoughts.

Studies on self-efficacy beliefs and procrastination have produced mixed results in literature. While findings of Wolters (2003), and Hannok (2011) show that procrastination is associated with a low level of academic self-efficacy, Schraw, Wadkins, and Olafson (2007) report in their findings that higher efficacy students rely on a deadline or some external motivators to spur them into action. Going by the findings of Wolters (2003), and Hannok (2011), it is expected that when a learner lacks sufficient belief in his or her capability to undertake a particular learning task, there is a tendency for such a learner to engage in avoidance- and delay-related behaviour tactics. However, it is important to emphasize that self-efficacy without the necessary self-regulatory cognitive skills and a strong sense of commitment may not actually produce the expected goal. This is because a tendency is there for a learner with a high level of self-efficacy to overrely on his or her capability and delay the execution of tasks till the last moment. Noran (2000) observes that academic procrastinators typically exhibit five cognitive distortions which consequently promote and maintain their task avoidance. These cognitive distortion behaviours, according to Akinsola, Tella and Tella (2007), include overestimation of time left 
to perform tasks, underestimation of time required in completing tasks, overestimation of future motivational states, misreliance on the necessity of emotional congruence to succeed at task, and the belief that working when not in the mood to work is sub-optimal.

\section{Academic Procrastination and Gender}

Gender difference in procrastinatory behaviour has been explored in a number of studies. Earlier studies (Effert \& Ferrari, 1989; Solomon \& Rothblum, 1984) report no significant gender difference in procrastinating behaviour. However, recent findings have reported gender differences in procrastination habits. While findings from Khan, Hafsa, Syeda, and Sidra (2014), Balkis and Duru (2009); Özer, Demir, and Ferrari (2009); Steel and Ferrari (2013), and Berkleyen (2017) report that males procrastinate more than their female counterparts, Washington (2004), Rodarte-Luna and Sherry report that female students procrastinate more. Contrarily, in terms of active/passive dimension of procrastination, Ismail (2016) finds no significant difference in active and passive procrastination scores of males and females.

In an attempt to push forward the frontier of knowledge on the phenomenon of procrastination in academic settings, there is a need to examine whether active and passive procrastinators differ in their academic self-efficacy beliefs. Also, understanding of procrastinatory behaviour of male and female undergraduates further enhances our knowledge of gender influence on behaviour. The specific objectives of this study are to:

- Examine the prevalence of academic procrastination among undergraduate students

- Determine the prevalent type of procrastinators among undergraduate students

- Examine the difference in academic selfefficacy of passive and active undergraduate procrastinators

- Examine gender association between passive and active undergraduate procrastinators

- Determine gender difference in procrastinatory behaviour of university undergraduates

\section{Research Questions}

1. What is the prevalence of academic procrastination among undergraduate students?

2. What is the prevalent type of procrastinators among undergraduate students?

\section{Research Hypotheses}

- There is no significant difference in academic self-efficacy of passive and active undergraduate procrastinators

- There is no significant gender association between passive and active undergraduate procrastinators.

- There is no significant gender difference in procrastinatory behaviour of university undergraduates.

\section{Method}

This study adopted a survey design. Survey is found appropriate for this study as it allows the researcher to gather information, summarize, present and interpret data for the purpose of clarification (Orodho, 2002). The sample for the study comprises 200 university undergraduates (male $=100$, female $=100$ ) selected across five different faculties (Arts =43, Communication and Information Sciences $=36$, Education $=47$, Social Sciences $=36$ and Sciences $=38$ ) within a university, using multistage sampling procedures. The age of the respondents ranges from 18-33 years, with 191 single and 09 married respondents. Three research instruments were used to collect data for the study. Those are: College Academic Self-Efficacy Scale (CASES) developed by Owen and Froman (1988), Tuckman Academic Procrastination Scale (TAPS) and Active Procrastination Scale (Choi \& Moran, 2009). College Academic Self-Efficacy Scale was used to collect data that measures academic self-efficacy of the undergraduates. Out of the 33 items in the original College Academic Self-efficacy Scale, 32 were adapted to suit the purpose of this study. The items were rated on a 5-point Likert-type scale ranging from "Very confident" = 5 to "Not at all confident" $=1$. Owen and Frowen (1988) report a Cronbach's alpha coefficient of .90 and a test retest reliability of .85 for the original scale. Ajayi, Sarkin Fada and Murja, (2015) also reported a Cronbach's alpha of .96 
when the 32-item scale was pilot-tested on 40 high school students.

Tuckman Academic Procrastination Scale (TAPS) was used in the study to collect the data that measure undergraduates' procrastination behaviour. This scale contains 16-items and according to Tuckman (1991), it was developed to assess undergraduates' tendency to procrastinate while carrying out different academic tasks and completing their college requirements. This is considered as an appropriate tool through which procrastination behaviour of undergraduates is detected as it provides a valid and reliable measure on procrastination tendencies such as wasting time on tasks, delaying, and intentionally putting off tasks that should have been done. Also, Ferrari, Johnson and McCown, (1995) assert that TPS provides a general index of academic procrastination which occurs as a result of students' ability to self-regulate or control their tasks schedules. The 16-items in TPS were rated on a 4-point Likert scale form ranging from "That's me for sure" $=4$, to "That's not me for sure" = 1 . However, items 7, 12, 14, and 16 were reversed in coding due to their positive nature. Responses to each item were cumulated for each respondent. Scores range from 16 through 64 , with higher scores on the scale reflecting higher level of procrastination. Students are then classified as Non-procrastinators (16-39), and Procrastinators (40-64). Tuckman reported .86 Cronbach's alpha coefficient for the scale in the original study while a Cronbach's alpha coefficient of 0.89 was reported in a recent study by the author (Tuckman, 2007). Also, other studies (Klassen, Krawchuck \& Rajani 2008; Klassen \& Kuzucu, 2009) reported Cronbach's alpha coefficient of 0.90 and while the scale was used to explore adolescents' procrastination in cross-cultural contexts, 0.81 was found for Singaporean and 0.88 for Canadian adolescents.
Active Procrastination Scale (Choi \& Moran, 2009) was used in this study to measure active/passive procrastination. APS consists of 16 items that measure four distinct characteristics of active procrastinators, which include outcome satisfaction, preference for pressure, intentional decision to procrastinate, and ability to meet deadlines. All items in this scale were rated on a 7-point Likert response format ranging from $1=$ Not at all true to $7=$ Very true. Individual responses to these items, with all the negatively worded items reversed, were summed up to form a composite measure to determine whether an individual is an active procrastinator or a passive one. Choi and Moran (2009) reported the reliability coefficients (Cronbach's Alpha) of four dimensions of the scale to range between .70 and .83 while the entire 16 - item scale yielded a reliability of .80 . The data obtained in the study was analysed using mean, standard deviation, independent t-test and chisquare test of independence. 


\section{Results}

\section{Research Questions}

Research Question 1: What is the prevalence of academic procrastination among undergraduate students?

Table 1: Prevalence of academic procrastination among undergraduate students $(N=200)$

\begin{tabular}{|l|r|r|r|r|}
\hline $\begin{array}{l}\text { Status on Academic } \\
\text { Procrastination }\end{array}$ & Mean & \multicolumn{1}{|c|}{ SD } & Frequency(f) & \multicolumn{1}{|c|}{ Percentage (\%) } \\
\hline Non procrastinators & 32.82 & 4.30 & 142 & 71.0 \\
\hline Procrastinators & 44.26 & 4.67 & 58 & 29.0 \\
\hline Total & & & 200 & 100.0 \\
\hline
\end{tabular}

Table 1 shows the results for the prevalence of academic procrastination among undergraduate students. As shown in this table, $58(29.0 \%)$ of undergraduate students are procrastinators while $142(71.0 \%)$ are non-procrastinators.

Research Question 2: What is the prevalent type of procrastinators among undergraduate students?

Table 2: Prevalent type of procrastinators among undergraduate students $(N=58)$

\begin{tabular}{|l|r|r|r|r|}
\hline $\begin{array}{l}\text { Types of Academic } \\
\text { Procrastination }\end{array}$ & Mean & \multicolumn{1}{|c|}{ SD } & Frequency(f) & \multicolumn{1}{|c|}{ Percentage (\%) } \\
\hline Pasive & 44.03 & 4.87 & 30 & 51.7 \\
\hline Active & 44.50 & 4.53 & 28 & 48.3 \\
\hline Total & & & 58 & 100.0 \\
\hline
\end{tabular}

Table 2 shows the results for the type of procrastinators among undergraduate students. It is shown that 30 $(51.7 \%)$ of the procrastinators are the passive type while $28(48.3 \%)$ are active procrastinators.

\section{Research Hypotheses}

HO1: There is no significant difference in academic self-efficacy of passive and active undergraduate procrastinators.

Table 3: T-test of difference in academic self-efficacy of passive and active undergraduate procrastinators $(N=58)$

\begin{tabular}{|c|c|c|c|c|c|c|c|}
\hline Academic Self-efficacy & $\mathbf{N}$ & Mean & SD & SEM & $\mathbf{t}$ & df & $\mathbf{P}$ \\
\hline Passive & 30 & 115.80 & 15.13 & 2.76 & \multirow{2}{*}{1.038} & \multirow{2}{*}{56} & \multirow{2}{*}{.304} \\
\hline Active & 28 & 110.75 & 21.56 & 4.08 & & & \\
\hline
\end{tabular}

Table 3 shows the difference in academic self-efficacy of passive and active academic procrastinators. It is shown that there is no significant difference in academic self-efficacy of passive, $(M=115.80, S D=15.13)$ and active $(M=110.75, S D=21.56 ; t(56)=1.038, p>.05)$ procrastinators.

It is shown that passive procrastinators have higher mean value than active procrastinators; however, the difference in these mean values is not considered significant at 0.05 level of confidence. Therefore, this result points to the conclusion that there is no significant difference in academic self-efficacy of passive and active undergraduate procrastinators. 
HO2: There is no significant gender association between passive and active undergraduate procrastinators.

Table 4: Chi-square analysis of gender association between passive and active undergraduate procrastinators $(N=58)$

\begin{tabular}{|c|c|c|c|c|c|c|}
\hline \multirow[t]{2}{*}{ Gender } & \multicolumn{2}{|c|}{ Procrastinators } & \multirow[t]{2}{*}{ Total } & \multirow[t]{2}{*}{$x^{2}$} & \multirow[t]{2}{*}{ df } & \multirow[t]{2}{*}{$\mathbf{P}$} \\
\hline & Passive & Active & & & & \\
\hline Male & 13 (43.3\%) & $17(56.7 \%)$ & $30(100.0 \%)$ & \multirow{3}{*}{1.752} & \multirow{3}{*}{1} & \multirow{3}{*}{.186} \\
\hline Female & $1760.7 \%)$ & 11 (39.3\%) & $28(100.0 \%)$ & & & \\
\hline Total & 30 (51.7\%) & 28 (48.3\%) & 58 (100.0\%) & & & \\
\hline
\end{tabular}

Table 4 shows the results for gender association between passive and active undergraduate procrastinators. It is shown that there is no significant gender association between passive and active undergraduate procrastinators, $\chi 2(n=58)=1.752, d f=1, p=.186$. Since $p$-value is greater than 0.05 level of significance, we do not reject the stated null hypothesis. This result therefore, leads to the conclusion that there is no significant gender association between passive and active undergraduate procrastinators.

HO3: There is no significant gender difference in procrastinatory behaviour of university undergraduates.

Table 5: T-test of gender difference in procrastinatory behaviour of university undergraduates ( $N=58)$

\begin{tabular}{|c|c|c|c|c|c|c|c|}
\hline Sex & $\mathrm{N}$ & Mean & SD & SEM & $t$ & df & $\mathbf{P}$ \\
\hline Male & 35 & 44.34 & 4.71 & .79 & \multirow{2}{*}{.168} & \multirow{2}{*}{56} & \multirow{2}{*}{.867} \\
\hline Female & 23 & 44.13 & 4.72 & .98 & & & \\
\hline
\end{tabular}

Table 5 shows gender difference in procrastinatory behaviour of university undergraduates. It is shown that there is no significant gender difference in procrastinatory behaviour of male $(M=44.34, S D=4.71)$ and female $(M=44.13, S D=4.72 ; t(56)=.168, p>.05)$ university undergraduates. It is, therefore, concluded that there is no significant gender difference in procrastinatory behaviour of university undergraduates.

\section{Discussion}

One of the findings of this study reveals that $29.0 \%$ of undergraduates are procrastinators. This finding indicates that university undergraduates engage in procrastination in their academic tasks, corroborating the outcome of Abu-Ghazal's (2012) study that not less than $25 \%$ of university students are procrastinators. It, however, contradicts Onwueglouzie's (2004) finding that approximately $40 \%$ to $60 \%$ of graduate students always or often procrastinate in such academic tasks as writing papers, preparing for tests, and reading assignments weekly. The observed difference in the outcome of this current study and that of Onwueglouzie (2004) can be attributed to the instruments used in measuring procrastination. While Onwueglouzie (2004) used Procrastination Assessment Scale-Students (PASS) developed by Solomon and Rothblum (1984), this present study used Tuckman Academic Procrastination Scale (TAPS) developed by Tuckman (1991). In addition, Onwueglouzie (2004) studied procrastination in
Statistics, a subject with more anxiety-provoking tasks whereas the current study focused on general academic tasks. It has also been revealed in this study that more than half of the sampled university undergraduates are passive procrastinators. This finding supports the earlier findings of Chu and Choi (2005) and Choi and Moran (2009) that procrastinators can be active or passive. However, the implication of this finding calls for concern as passive procrastination is characterized by irrational and counterproductive delay. In other words, students demonstrating passive procrastinatory behaviour are characterized by failure in self-regulation (Steel, 2007).

It has further been revealed that there is no significant difference in academic self-efficacy of passive and active undergraduate procrastinators. This suggests that academic self-efficacy of the individual does not contribute to whether the task will be done on time 
or after an unnecessary delay. This finding contradicts the findings of Wolters (2003) and Hannok (2011) that procrastination is associated with low level of academic self-efficacy.

Another conclusion reached in this study is that there is neither a significant gender association between passive and active undergraduate procrastinators nor a significant gender difference in procrastinatory behaviour of university undergraduates.

According to the findings of this study, none of the aspects of procrastinatory behaviour can be attributed more to one gender than the other. In addition, the findings reveal that procrastinatory behaviour of university undergraduates is not gender inclined. These findings support the findings of Ismail (2016), who found no significant difference in active and passive procrastination scores of males and females. The findings, however, contradict the findings of researchers such as Khan, Hafsa, Syeda, and Sidra (2014), Balkis and Duru (2009); Özer, Demir, and Ferrari (2009); Steel and Ferrari (2013), and Berkleyen (2017), who all reported that males procrastinate more than their female counterparts.

\section{Conclusion}

The study concludes that university undergraduates engage in procrastinatory behaviour in their academic tasks. More than half of these undergraduates are passive procrastinators. Academic self-efficacy of passive and active undergraduate procrastinators does not differ significantly. Gender is not a significant factor while considering procrastinatory behaviour of university undergraduates.

\section{Recommendations}

It is therefore recommended that seminars on selfunderstanding in relation to learning should be organized for university undergraduates. Through this, individual undergraduates might become aware of themselves and their behaviour in relation to academic commitments. 


\section{References}

» Abd-Elmotaleb, M., \& Saha, S. (2013). The role of academic self-efficacy as a mediator variable between perceived academic climate and academic performance. Journal of Education and Learning, 2(3), 117-129.

» Abu-Ghazal, M. (2012). Academic procrastination: Its prevalence and causes from the perspective of university students. Jordanian Journal of Educational Sciences, 8 (2), 131-150.

» Aderanti, R. A., Williams, T. M., Oyinloye, T. M. \& Uwanna, N. C. (2013). Academic procrastination, overconfidence and parental unrealistic expectations as correlates of academic rebelliousness among some Nigerian Undergraduate students. The African Symposium, 13(1), 12-18.

» Ajayi, O. S., Sarkin Fada, H., \& Murja, L. M. (2015). Academic self-efficacy and students' classroom engagement in public senior secondary schools in Osun central senatorial district. Nigerian Journal of Educational Foundations, 14(1), 2-15.

» Akinsola, M. K.; Tella, A. \& Tella, A. (2007). Correlates of academic procrastination and Mathematics achievement of University Undergraduate Students. Eurasia Journal of Mathematics, Science \& Technology Education, 3(4), 363-370.

» Balkis, M., \& Duru, E. (2007). The evaluation of the major characteristics and aspects of the procrastination in the framework of psychological counseling and guidance. Educational Sciences: Theory \& Practice, 7(1), 376-385.

» Beck, B. L. \& Koons, S. R, Migram, D. L. (2000). Correlates and consequence of behavioural procrastination: The effects of academic procrastination, self- consciousness, self-esteem, and self-handicapping. Journal of Social Behaviour and Personality, 15, 3-13.

" Bembenutty, H., \& Karabenick, S. A. (2004). Inherent association between academic delay of gratification, future time perspective, and self-regulated learning. Educational Psychology Review, 16(1), 35-57.

»Choi, J. N., \& Moran, S. V. (2009). Why not procrastinate? Development and validation of a new active procrastination scale. Journal of Social Psychology, 149(2), 195-212.

»Chu, A. H. C., \& Choi, J. N. (2005). Rethinking procrastination: Positive effects of "Active" procrastination behavior on attitudes and performance. Journal of Social Psychology, 145(3), 245-264.

» Berkleyen, N. (2017. Understanding the academic procrastination attitude of language learners in Turkish universities. Educational Research and Review, 12(3), 108-115

"Ferrari, J. R., \& Emmons, R.A. (1995). Methods of procrastination and their relation to self-control and selfreinforcement: An exploratory study. Journal of Social Behaviour and Personality, 10, 135-142.

» Freeman, E., Cox-Fuenzalida, L., \& Stoltenberg, I. (2011). Extraversion and arousal procrastination: Waiting for the kicks. Current Psychology, 30(4), 375-382.

» Fritzsche, B. A., Young, B. R., \& Hickson, K. C. (2003). Individual differences in academic procrastination tendency and writing success. Personality and Individual Differences, 35, 1549-1557.

» Gupta, R., Hershey, D., \& Gaur, J. (2012). Time perspective and procrastination in the workplace: An empirical investigation. Current Psychology, 31(2), 195-211.

» Hannok, W. (2011). Procrastination and motivation beliefs of adolescents: A cross-cultural study. Unpublished PhD Dissertation, University of Alberta.

» Howell, A. J., \& Watson, D. C. (2007). Procrastination: Associations with achievement goal orientation and learning strategies. Personality and Individual Differences, 43(1), 167-178.

» Ismail, D. (2016). Psychological well-being and its relationship with active and passive procrastination: A study of students of a business university in Karachi. Academic Journal of Interdisciplinary Studies, 5(3), 86-94.

» Kachgal, M. M., Hansen, L. S., \& Nutter, K. J. (2001). Academic procrastination prevention/intervention: Strategies and recommendations. Journal of Developmental Education, 25, 14-21.

» Khan, M. J., Hafsa, A., Syeda, S. N., \& Sidra, M. (2014). Academic procrastination among male and female university and college students. FWU Journal of Social Sciences, 8(2), 65-70.

» Kim, R. K. \& Seo, E. H. (2015). The relationship between procrastination and academic performance: A meta-analysis, Personality and Individual Differences, 82, 26-33.

» Klassen, R. M., \& Kuzucu, E. (2009). Academic procrastination and motivation of adolescents in Turkey. Educational Psychology, 29(1), 69-81. 
Klassen, R. M., Krawchuk, L. L., \& Rajani, S. (2008). Academic procrastination of undergraduates: Low selfefficacy to self-regulate predicts higher levels of procrastination. Contemporary Educational Psychology, 33(4), 915-931.

»Noran, F. Y. (2000). Procrastination among students in institutes of higher learning: Challenges for K-Economy. Available at: http://www.mahdzan.com/papers/procrastinate/

» Onwuegbuzie, A. J. (2004). Academic procrastination and statistics anxiety. Assessment Evaluation of Higher Education, 29(1), 3-19.

» Ozer, B.U., Demir, A., \& Ferrari, J. R. (2009). Exploring academic procrastination among Turkish students: Possible gender differences in prevalence and reasons. Journal of Social Psychology, 149, 241-257.

»Pajares, F. (1996). Self-efficacy beliefs in academic settings. Review of Educational Research, 66(4), 543578.

"Popoola, B. I. (2005). A study of the relationship between procrastinatory behaviour and academic performance of undergraduate students in a Nigerian University. African Symposium: An Online Journal of Educational Research Network.

» Rodarte-Luna, B., \& Sherry, A. (2008). Sex differences in the relation between statistics anxiety and cognitive/learning strategies. Contemporary Educational Psychology, 33(2), 327-344.

» Rozental, A., \& Carlbring, P. (2013). Internet-based cognitive behavior therapy for procrastination: Study protocol for a randomized controlled trial. Journal of Medical Internet Research, 15(11), 27.

» Savithri, J. J. (2014). Interactive effect of academic procrastination and academic performance on life satisfaction. International Journal of Science and Research (IJSR), 3(3), 377-381.

» Schraw, G., Wadkins, T., \& Olafson, L. (2007). Doing the things we do: A grounded theory of academic procrastination. Journal of Educational Psychology, 99, 12-25.

» Schubert, W., Lilly, J., \& Stewart, D. W. (2000). Overcoming the powerlessness of procrastination. Guidance and Counseling, 16(1), 39-43.

» Schunk, D. H. (1991). Self-efficacy and academic motivation. Educational Psychologist, 26, 207-231.

» Solomon, L. J. \& Rothblum, E. D. (1984). Academic procrastination: Frequency and cognitive behavioural correlates. Journal of Counseling Psychology, 31, 503-509.

»Steel, P. (2007). The nature of procrastination: A Meta-Analytic and theoretical review of quintessential self-regulatory failure. Psychological Bulletin, 133(1), 65-94.

» Steel, P., \& Ferrari, J. (2013). Sex, education and procrastination: An epidemiological study of procrastinators' characteristics from a global sample. European Journal of Personality, 27(1), 51-58.

» Tice, D. M, \& Baumeister, R. F. (1997). Longitudinal study of procrastination, performance, stress and health: The costs and benefits of dawdling. Psychological Science, 18, 454-458.

» Tuckman, B. W.; Abry, D. A. \& Smith, D. R. (2002). Learning and motivation strategies: Your guide to success. Upper Saddle River, N.J: Prentice-Hall.

»Wang, J., Sperling, R. A., \& Haspel, P. (2015). Patterns of procrastination, motivation, and strategy use across class contexts and students' abilities. Journal of Psychology and Behavioral, 3(2), 61-73.

»Washington, J.A. (2004). The relationship between procrastination and depression among graduate and professional students across academic programs: Implications for counseling. Unpublished doctoral dissertation, Texas southern university, Texas.

»Wesley, J. (1994). Effects of ability, high school achievement and procrastinatory behaviour on college performance. Educational and Psychological Measurement 54, 404-408.

»Wolters, C. A. (2003). Understanding procrastination from a self-regulated learning perspective. Journal of Educational Psychology, 95, 179-187.

» Zimmerman, B. J. (2000). Self-efficacy: An essential motive to learn. Contemporary Educational-Psychology, 25(1), 82-91. 